\title{
Cinema Transcendental
}

\section{Alexandre de Oliveira Torres Carrasco}

Universidade Federal de São Paulo - Unifesp

\section{RESUMO}

O presente artigo pretende correlacionar elementos críticos e teóricos de certa filosofia francesa, a filosofia francesa que emerge no entreguerras, com elementos críticos (e em alguma medida práticos) que operam na formação da crítica moderna de cinema na França. O sentido dessa correlaçáo é apresentar as possibilidades de uma investigação conjunta com o fim de uma renovação da compreensão e do alcance de ambos empreendimentos.

\section{PALAVRAS-CHAVE}

Filosofia Francesa Contemporânea; Existencialismo; Merleau-Ponty; Crítica; Cinema.

\begin{abstract}
The present article intends to correlate critical and theoretical elements of a certain French philosophy, the French philosophy that emerges after World War II, with critical (and to some extent practical) elements that operate in the formation of modern cinema criticism in France. The meaning of this correlation is to present the possibilities of a joint investigation with the aim of renewing the understanding and scope of both projects.
\end{abstract}

\section{KEY WORDS}

Contemporary French Philosophy; Existentialism; Merleau-Ponty; Criticism; Cinema. 


\author{
"La hipótesis de que las imágenes tengan alma \\ parece confirmada por los efectos de mi máquina \\ sobre las personas, los animales y los vegetables emisores." \\ La invención de Morel, Adollfo Bioy Casares.
}

Em março de 1945 Merleau-Ponty faz uma conferência no Instituto de Altos Estudos Cinematográficos, cujo título é $O$ cinema e a nova psicologia. Tal conferência, publicada em Sens et non-sens, de 1948 (antes republicado em Les Temps Modernes, no. 7, abril de 1947) é índice de importantes cruzamentos, teóricos e práticos, em curso naquele momento, dando relevo a vários aspectos chaves, seja da filosofia montante daquela época, "o momento filosófico da segunda guerra mundial, a existência”, seja da filosofia do próprio Merleau-Ponty, parte de um projeto aproximadamente comum, o que Worms chama de "momento", e nós o adotamos provisoriamente o nome e o conceito. A se pensar sobretudo naquele ponto temporal específico, algo entre 1945 e 1950, as diferenças a se constituir no interior de um mesmo "bloco", de um mesmo "momento", estavam decididamente esmaecidas seja pela euforia da libertaçáo, seja pelas tarefas que o fim do ciclo intelectual da Terceira República impunha. Soma-se a isso a potência teórica especificamente merleaupontyana em tratar de temas estranhos à teoria de modo teórico, potência essa que foi, naqueles idos, credencial necessárias dos jovens filósofos então para a irrupção das novas filosofias de antanho. Sens et non-sens é testemunha exemplar disso.

Portanto, a primeira atenção que tomamos, em boa medida prévia, é localizar este momento do qual Merleau-Ponty faz parte, o que não se faz despropositadamente, pois é sua localização "lógica", por assim dizer, que torna mais compreensível seu alcance e as tarefas que toma como as suas. Falamos de um momento incrustrado no bloco maior da Filosofia Francesa Contemporânea, cuja referência à Filosofia Francesa pura e simplesmente nos levaria, não sem algum percalço, até Descartes, respondendo Montaigne. Naturalmente não é esse o caso. $\mathrm{O}$ fato é que o corte crítico-historiográfico de Worms, a Filosofia em França no século XX e seus momentos (Worms, 2009) é sem dúvida heurístico e não o é sem que tomemos a liberdade de fazer remissão a outro livro, como o faz o próprio Worms, sobre o mesmo tema, hoje um tanto menos famoso, O mesmo e o outro, de V. Descombes (1979). Um e outro, com uma distância de trinta anos, perfazem o mesmo recorte, ainda que com critérios analíticos distintos. $\mathrm{O}$ empreendimento de Descombes náo deixa te manter certa higidez quando se nota que, para além daquilo que podemos chamar de diferenças de geração, de corte meramente geracional e cronológico, ele repertoria essas diferenças pelo recorte das "influências" (naturalmente é mais que isso, lembrando que a palavra em si mesma - "influência” - é problemática). A passagem da geração dos três $\mathrm{H}$ (Husserl, Heidegger e Hegel, a que nos interesse 
nesse texto), sob influências de influxo da fenomenologia alemã e o que era entendido como tal, à geraçấo dos "Mestres da Suspeita" (Freud, Marx e Nietzsche), fazse por uma diferença de autores que igualmente decorre da eleiçáo de temas e os modos dessa eleição. O efeito visível dessa diferença dá-se na diferença específica do cânon que cada momento elege, autores diversos para tarefas diversas, num jogo sutil de afinidades de formas e conteúdos. A geração do entre guerras é tanto aquela que leu preferencialmente certos filósofos (os três $\mathrm{H}$ ) quando a que pode se ver neles como num espelho, a traduzir os seus problemas e limites naquelas imagens que colhia na recém estabelecida história da filosofia. Logo, essa orientação bibliográfica, digamos assim, é muito menos arbitrária do que parece, e responde, sim, (ainda que parcialmente) a um tipo de organicidade decorrente da formação de um gênero, a história da filosofia, que o livro de Worms explora como o pressuposto mais geral da passagem de armas entre geraçóes. Assim, apesar do estardalhaço da superfície, com Politzer batendo o bumbo (um dos marcos do fim do espiritualismo Belle Époque), a geração pós Bergson redesenha o problema do neokantismo francês a partir da junção de duas peças mais ou menos heteróclitas: a versão especialíssima que dá o próprio Bergson do neokantismo à medida que acompanhando o sentido geral do neokantismo, a reelaboração das relações entre sensibilidade e entendimento, afastase fatalmente dessa tradição, pois recoloca nessa reelaboraçáo a intuição como um elemento chave de sua filosofia, uma intuição que se desdobra em metafísica, mal resumindo. O esforço do neokantismo é o contrário ${ }^{1}$, sobretudo: ao redefinir as relaçóes entre sensibilidade e entendimento, sobretudo diante do que se passa e do que passa a ser a ciência ao longo do século XIX, ele pretende escapar a toda forma de intuicionismo, assumindo praticamente de partida que a própria matemática náo passa pela intuição, como acreditava o patrono do método transcendental, pai de todos, Kant. Ora, Bergson oferece essa inflexão paralelamente a uma tradição neokantiama também é francesa (Le Roy, Renouvier, Boutroux, Meyerson, Brunschwig). O chamado neokantismo francês, e cuja fim também era, ao banir qualquer veleidade intuitiva, salvaguardar uma regiáo específica de objetos que passa a definir um gênero, a filosofia como teoria da ciência, em sentido largo, regiáo essa que, ao fim e ao cabe, deve ser de objetos negativos, a teoria da ciência que finalmente se torna a conhecida teoria do conhecimento. Digamos, rapidamente, que essas duas pontas do "espiritualismo" é o legado que recebem nossos, então, jovens filósofos, especialmente Merleau-Ponty.

1 Sobre isso, sugerimos Porta, 2011, sobretudo p. 92-93. 
Ocorre que o ambiente bergsoniano da filosofia francesa, tendo como fundo o debate neokantiano, mas dando-lhe um arremate inusitado e particular, se criava uma área de escape para a assepsia do neokantismo, náo era suficiente para, por si, dar conta da dupla tarefa que se impunha: avançar uma casa e deixar o próprio Bergson para trás, e reabilitar aquilo que a repulsa reiterada, por quase um século, da intuição (repulsa que que constitui pari passu com a filosofia universitária francesa) vedava, o retorno ao "concreto", que não poucas vezes se identificava com o imediato e com o intuitivo.

Para tal foi necessário importar uma filosofia alemã, que também navegava nos entornos da tradiçáo neokantiana, mas que, por diferença específica, punha suas questôes de outro modo, a reabilitar aquilo que ela chamava, não sem alguma ambiguidade num primeiro momento, de retorno "às coisas elas mesmas". Eis a chegada da fenomenologia, que a despeito de certas afinidades com Bergson, opera, em sua aclimatação, também como crítica ao bergsonismo, pela razão, evidente então, de, ao fim e ao cabo, Bergson náo ter sido suficientemente "concreto".

As voltas que fazemos não se pretendem, claro, tão gratuitas. Retomemos o fio da meada: o texto de Merleau-Ponty, eixo de nossa exposição, O cinema e a nova psicologia, insere-se, pois, e a intenção é dar-lhe esse relevo, em um "momento" da filosofia francesa com as seguintes característica: escapando do isolamento anti-intuitivo que caracterizou o neokantimos francês, isto é, da reitera restrição à região de objetos legítima à investigaçáo, a chegada da fenomenologia e seu arsenal de elementos críticos e intuitivos torna viável uma crítica por dentro do neokantimos capaz de reabilitar, em uma via não propriamente bergsoniana, um espaço de investigação teórica náo rigidamente epistemológico (que tomamos aqui como estritamente negativo, tratando das condiçóes de possibilidade do conhecimento). Essa reorientação do espírito, digamos assim, que segue pari passu com a reabilitação da intuição (algo não estranho à filosofia husserliana, e que, portanto, reativa certos elementos latentes se náo de Bergson, ao menos do bergsonismo) repóem em outro registro as ambiçôes de uma filosofia do "concreto" da qual aquela geração teria tido notícia por meio dos melhores momentos da filosofia bergsoniana.

Como efeito de uma rebuscada (ou rocambolesca?) aclimataçáo de uma teoria do conhecimento especial, desdobra-se e "descobre-se" uma série de assuntos "exóticos", que antes estava esterilizados pelo cordão sanitário do neokantimos francês, e que repentinamente podem ser reabilitados ou habilidades, a depender do juízo do crítico $^{2}$. Ela mesma, a fenomenologia, algo excêntrica em relação ao ambiente

\footnotetext{
2 Ver "Husserl: significação e existência", in Moura, 2001. À parte a ironia, Carlos Alberto Ribeiro de Moura faz
} um corte à navalha muito preciso, a separar o destino transcendental da fenomenologia, a abertura do artigo, 
teórico de que fazia parte, já que ficava, a saber, grosso modo, entre o logicismo fregeano e o neokantimos propriamente dito, realiza, além-fronteiras, essa proeza, não sem custo teórico.

Essa inflexão se dá no interior de um gênero, ${ }^{3}$ em processo de consolidação, que oscila entre a história da filosofia e a filosofia universitária, e tem a ver com o estabelecimento da filosofia em novas condiçóes profissionais e objetivas como gênero autônomo.

A consciência do espaço teórico que se abre por meio dessa inflexão, que no fim das contas não é meramente especulativa, é que torna possível o texto merleaupontyano, sobre o qual nos detemos. De modo que, diante desse movimento, tratar do cinema não é excêntrico nem diversionista. É um tipo específico de ensaio teórico, tornado possível por força dessa reviravolta no bloco hegemônico da filosofia francesa de então.

Até o momento recompomos algo como o lugar "lógico" dele no interior de um movimento específico da Filosofia Francesa Contemporânea e seus condicionantes, repondo os elementos tradicionais e inovadores do esforço de seu móvel teórico. A partir desse lugar, tomado, de nossa parte, como mediação necessária, podemos seguir com nossa pretensão de lhe dar algo como um duplo tratamento.

A pretensão explica-se do seguinte modo: uma vez estabelecidas as coordenadas mínimas de localização do texto, podemos, na sequência: primeiro, entende-lo como parte de um movimento mais amplo de crise, o final de um ciclo teórico e prático que se encerra, ainda que de forma mitigada, a se olhar com mais distância, como olhamos: a crise e o fim estrepitante da Terceira República francesa, do qual o "cinema" (no seu sentido mais geral) igualmente faz parte. $O$ fato de o cinema fazer parte, à sua maneira, não diz tudo; é mais do que isso: de certo modo ele conflue como efeito de uma mesma vaga que tomou a filosofia, tese que só ficará esclarecida no fim desse texto. Daí nossa chave de leitura: é possível compreender

apresentando-o como inegociável, e o debate em torno do psicologismo (e do antipsicologismo), digamos, na esteira desse destino, a porta lateral de que faz uso a Filosofia Francesa para alcançar a fenomenologia. Sem que seja precisa explicitar, fica claro que a via de acesso da filosofia francesa à fenomenologia se dá por meio desse debate fenomenológico subsidiário, e talvez a palavra seja forte demais, diríamos, já nos corrigindo, não central, lateral, em torno de certa duplicidade lógica e psicológica da intencionalidade, só purificada pela redução. Merleau-Ponty não deixa de ser certeiro ao tomar o tema da redução como central, tratando de construir inúmeras barreiras para a não adesão estrita à noção husserliana. (Ver Merleau-Ponty, 1945, p. VIII-XIX). A filosofia francesa da existência como que se aproveita disso e retraduz a dimensão "psicológica" do ato (da consciência e por extensão da intencionalidade) como pedra de toque para conhecer o mundo, um mundo reabilitado justamente por essa intencionalidade que retraduz tudo a tudo. Não mais o mundo anti-anímico de Galileu e que reaparece em regime metafísico sob a pena de Descartes como res extensa, mas o mundo do horror da máscara japonesa tal como descreve Sartre em seu famoso texto sobre a intencionalidade. Vale a citaçáo de Carlos Alberto Ribeiro de Moura: "Donde se pode começar a medir a envergadura da herença husserliana na reflexão da existência, tal como ela se transporta do mundo fenomenal a esses outros mundos, que também se constituirão a partir da recusa de qualquer assimilação à natureza: o mundo "pré-objetivo" e o "existencial”, novos nomes do lugar habitado pelo logos fenomenal”. (Moura, 2001, p. 183). Sobre o psicologismo e o modo pelo qual Husserl se insere nesse debate, ver igualmente Porta, 2013.

3 Ver Bianco, 2020. 
um pelo outro, tomando o caso específico dessa relação, de que o texto merleaupontyano dá testemunha. É possível entender o sentido crítico do texto merleaupontyano entendendo a cultura da crítica cinematográfica que se formava pari passu a nova vaga da filosofia francesa. Portanto, reforçamos: é possível constatar um sentido mais geral de renovação que se espraia em diversos casos, entre eles a filosofia e o cinema. No caso da filosofia, pela condiçóes teóricas e práticas da passagem do espiritualismo às filosofias da existência, no caso do cinema, pela formação da crítica moderna de cinema, que acompanha pari passu o estabelecimento de uma cultura cinéfila, o que reatualiza em nova chave os salóes do século XIX.

Feita essa constatação, vejamos o nosso segundo ponto: trata-se de reativar, na medida do possível e nos limites desse artigo, a agudeza da percepção merleaupontyana sobre o cinema, por dentro, e em perfeita sintonia com a renovação da crítica cinematográfica que aquele fim de ciclo que acabamos de mencionar exigiu e pôs em curso, cujo fim da segunda guerra instauramos como um marco cronológico. Dessa constatação mais ampla, da convergência formal entre a nova filosofia e a critica cinematográfica que se gesta no início dos anos 40, é que tiramos o seguinte corolário, algo como uma segunda camada de interpretaçáo do texto merleaupontyano: é possível constatar o quanto o texto em questáo, por seu turno, anunciava ainda que náo claramente no momento específico em que era escrito e pensando uma nova visualidade (ou uma nova "visibilidade") cinematográfica ao repetir sua toada de crítica empíreo-intelectualista e "reabilitação" da percepção como que plasmadas às agudas passagens críticas de Leenhardt, que Merleau-Ponty toma de empréstimo em seu texto. Será essa nova visualidade anunciada que dará o húmus do quer seria chamado, com mais ou menos três décadas de distância, de o moderno cinema francês. Desse último ponto de vista, o texto merleaupontyano, de certo modo o antecipa, em observando certas mediaçóes, o mais importante ciclo cinematográfico francês depois de Jean Renoir e Jean Vigo, e o cinema mudo. O que pretendemos esboçar aqui são os motivos que fazem essa configuração de elementos convergiram para um inesperado ar de parentesco que o próprio Merleau-Ponty indica explicitamente no fim de sua conferência.

Um dos índices chaves do texto merleaupontyano, por óbvio, é a natureza do tratamento teórico dado ao tema, se podemos falar nesses termos, sem incorrer, entretanto, em uma teoria do cinema. Ora, o busílis teórico que possibilita isso, reforçamos, tem a ver com o modo como a fenomenologia é agenciada pela geração filosófica montante em sua chegada à França, sob o fundo das condições de recepção que indicamos de passagem acima, vale notar, tudo, pelas melhores ou piores razóes. Inevitável não retomar o texto de Carlos Alberto Ribeiro de Moura: "Se a realidade humana não é um somatório de fatos - diz ele [Sartre] - então nada é acidental, já 
que tudo exprime, sob um aspecto, o todo. Donde o benefício último da fenomenologia para a reflexão sobre a existência: graças a ela, agora nada mais é fortuito" (Moura, 2001, p. 183). Logo, para mal resumir, a possibilidade de um tratamento ensaístico e teórico está dada pelo modo pelo qual a fenomenologia é aclimatada às condiçóes espirituais francesas, a releitura francesa do sentido de fenômeno, significação e expressão, digamos assim, no momento em que a filosofia, a partir da experiência específica do século XIX, marcado pelos debates implícitos em torno da "história da filosofia" e da "filosofia universitária", toma para si as vantagens e desvantagens de ser um "gênero" autônomo, capaz de falar das "coisas", e de todas as coisas. Isso, que tem implicaçóes de curto e longo alcance, como se pode ver, só nos interessa, pois torna possível, com mais precisão, vislumbra o recorte epistemológico que torna factível o texto merleaupontyano, afastando em definitivo as leituras que o tomariam por diversionismo de ocasiáo.

Pois bem, a conferência é publicada em versão definitiva no livro ${ }^{4}$ de 1948, livro que é, sem dúvida, o mais "existencialista" dos livros de Merleau-Ponty e que traduz, à sua maneira, à maneira merleaupontyana, o clima de ruptura e renovaçáo típico daquele imediato pós-guerra francês, ainda sob à sombra portentosa do díptico Resistência e Libertação, sejam mitos ou não, o avesso do debacle da Terceira República, o outro lado da moeda. Retomando nossa tópica, há uma boa quadra a Terceira República já não era claramente funcional, e os anos trinta na França são um depositário de todo tipo de radicalismo 5 (de resto, o fenômeno também é, em boa medida, europeu). O permanente impasse da Terceira República, cujo arco de afliçóes pode ser marcado desde pelo menos o caso Dreyfuss, é tornado agudo em 1936, com o primeiro governo da Frente Popular. A crise final da Terceira República, a capitulação e a República de Vichy, provavelmente tem início antes do primeiro gabinete de León Blum, mas fiquemos com o óbvio.

$\mathrm{O}$ fato é que a miríade de temas que o livro percorre, e não são poucos, dispersos na aparência, mas só na aparência, traduz esse agenciamento novo que circunscrevemos, e que se reflete em temas e problemas "inéditos" (com aspas, pois, de fato, eram temas que, se entendidos como temas mundanos lato sensu, sob outras condiçóes, davam-se igualmente como material para ilustração francesa do XVIII), tudo muito próprio às filosofias montantes daqueles idos, e cuja orientação chave parece ser a de uma filosofia que faz menos o papel de uma teoria das coisas ou de uma teoria do conhecimento (das coisas), e mais a de um modo teórico de aproximação das "coisas elas mesmas" (em se tratando do uso e abuso da expressão husserliana, um dos

4 Merleau-Ponty, 1996 [1948], "Le cinéma et la nouvelle psychologie", p. 61-74.

5 Ver Judt, 2007, sobretudo p. 29 e ss. 
equívocos mais frutíferos da história recente da filosofia francesa) ${ }^{6}$. Mal resumindo, as filosofias do concreto, com algumas divergências entre si, porém concordando com um sentido geral para fins de orientação: em direção às coisas elas mesmas. Se a diferença entre uma teoria em sentido próprio e aproximação teórica das coisas é tangível teoricamente, embora pareça que sim, esse é um problema que, apesar do evidente interesse, escapa do escopo de nosso texto. Daí que nos limitaremos a tratar do seguinte: mais do que dar relevo ao tratamento teórico e fino que dá MerleauPonty a um tema entáo não pacífico, o cinema e seu estatuto, interessa-nos acompanhar o quanto a formação da filosofia pós 45 (1945) converge com a formação da moderna crítica de cinema francesa (e, por extensão, com o cinema moderno francês) em um movimento surpreendentemente coincidente. Essa coincidência não deixa de ser objeto privilegiado para uma possível história da ideologia francesa do século XX, o que indicamos a intenção, a ser perseguida em outro tempo e lugar.

Sigamos assumindo a atitude natural daqueles tempos, no exemplo único que nos dá Sens et non-sens. Entre problemas, conceitos, temas políticos, estéticos e especulativos (ou técnicos), a redescoberta de filósofos que passam a dar relevo a um novo debate (Hegel e Marx, por exemplo), e linhas de ocasiáo, ainda sim agudas em seu prosaísmo, aparece o cinema que, em correlação com "a nova psicologia” do título, estava em via de ser posto em correlação com a nova filosofia daqueles anos. Lembrando, a propósito, que a Revista Les Temps Modernes, de ano de nascimento, o ano da graça de 1944, por mais de uma década a mais importante revista teórica europeia, projeto do qual Merleau-Ponty foi elemento chave até a ruptura com Sartre em meados dos anos 50, faz referência explícita ao cinema, o indiscutível clássico do cinema mudo, homônimo, bem como tem papel importante no reconhecimento do estatuto intelectual da crítica de cinema nascente naqueles idos, ao publicar, num feliz encontro, a crítica de Sartre a Cidadão Kane (Orson Welles, 1941) e a resposta de André Bazin (Baecque, 2003, p. 42) a crítica sartreana.

Tomando o livro de Merleau-Ponty, podemos dizer que a unidade do livro, e há, viria de uma filosofia capaz de tragar ao seu interior, como legítimos problemas especulativos, temas usualmente mundanos e prosaicos - a pintura moderna, o romance, a política do dia a dia, a biografia e, enfim, o cinema - num esforço único e a contracorrente da discrição e da contenção epistemológica de antanho, hábito intelectual obrigatório de há um século, repentinamente ultrapassado.

Registre-se o frescor do livro, em parte, o frescor daqueles anos, em que as inúmeras expectativas vindas com a libertação e o fim da guerra ainda não teriam sido

6 "Linguagem e Experiência em Merleau-Ponty", in Moura, 2001. 
fatalmente contaminadas pelas ilusóes hoje sabidas, e naquele momento, ilusão das ilusões, em boa parte inesperadas. A história está toda lá, e é o que nos faz crer Antoine de Baecque, no seu magnífico La cinephilie. Invention d'un regard, histoire d'une culture, 1944-1968. Mal resumindo, no momento em que Merleau-Ponty publica sua conferência, está em curso, se se permite a imagem de uma imagem, a formação do olhar do moderno do cinema francês, que se dá não sem que antes se perfaça o percurso negativo dessa formação, a crítica interessada, cujos melhores resultados e quadros desembocam no famoso Cahiers du Cinema, capa amarela, o antecedente negativo da Nouvelle Vague ${ }^{7}$. Uma vez feito isso, e o negativo aqui é, com soe acontecer, o ajuste formal da consciência com o seu tempo, falando em linguagem hegeliana, estar-se-á prestes a desembocar propriamente na Nouvelle Vague, a nova onda que deságua mais ou menos entre 1955 e 1959, a depender do humor do crítico, digamos simplesmente entre La Pointe-Courte, de Agnes Varda e Le quatre cents coups, de François Truffaut (Beadque, 1991, p. 295). Assim, o texto merleaupontyano tem interesse impar: não se trata apenas de um inusitado e algo inédito agenciamento filosófico dos problemas concernentes a uma arte duvidosa (ainda, digamos, apesar e em respeito a Renoir e Vigo), mas de algo mais, algo em consonância com aquele tempo contido e em parte subvertido que o fim da ocupação liberara em energia, da cinefilia às filosofias do concreto, efeitos e sintomas de, em uma parte, o esfacelamento e a ruína da Terceira República Francesa, em outra parte, do rearranjo e da permanência inesperada de elementos daquele mesmo ciclo histórico terminal.

Se fizermos uma história de ocasiáo desse último grande ciclo do cinema francês moderno, cujo começo e fim coincide com as filosofias em questão, outra coincidência, um e outro acompanhando os ares daqueles tempos, o "momento" 1945 (Worms) em sua história da Filosofia na França (Worms, 2009) ${ }^{8}$, a cronologia do "momento" das "filosofias do concreto", reencontramos ambos em 1968, juntos, o fim do cinema moderno francês, e o marco fatal do fim da hegemonia dos "anos Sartre", com outros fins subsidiários: o "fim" do sujeito, da história, da dialética, etc., todos arrasados pelos impasses, traumas e derivas daquela famosa primavera, que curiosamente começa em fevereiro com a fronda dos cineastas em defesa da cinemateca. Essa coincidência não é trivial nem propriamente coincidência, registre-

\footnotetext{
7 Sobre os Cahiers du cinema veja Beadque, 1991.

8 "Jamais sans doute la question d'hérö̈sme ne fut plus brûlant pour la philosophie que pensant la Seconde Guerre mondiale en France, et cela pour deux sortes de raisons : pour de raison historiques, tenant à l' 'engagement' - ou pas - des philosophes dans l'action, mais aussi - sans que l'on puisse entièrement les séparer pour des raisons philosophiques, que font rétrospectivement de ce problème, celui du héros, l'un des révélateurs privilégiés de ce moment philosophique central du siècle, dans toute sa diversité." (Worms, 2009, p. 439).
} 
se aqui ${ }^{9}$. O fim do ciclo do moderno cinema francês é o inevitável corte em dois tempos daquela película. Daquele tempo até o nosso, a decupagem e montagem de um olhar exige outra técnica. Também disso tratamos aqui, se nos permitem a impertinência.

Voltando à nossa primeira tentativa de descrição dos antecedentes materiais do texto merleaupontyano, o primeiro momento, a clara indicação no texto merleaupontyando do lugar de que parte, não pode passar desapercebido. A referência explícita ao crítico Roger Leenhardt, e seus textos na Esprit de 1936, exigem, de per se, uma panorâmica.

Assim, parece-nos, essa camada mais anterior da formação a que fazemos referência (da crítica e do olhar) está nos antecedentes necessários à crítica cinematográfica, a que culmina na sua consolidação quando do ciclo amarelo do Cahiers $d u$ Cinema (os primeiros doze anos da revista com a característica capa amarela), elemento negativo chave na Nouvelle Vague, o cinema moderno francês em sentido próprio, com os jovens turcos distribuindo verdades críticas, custe o que custar (Truffaut, Godard, Rivette, Rohmer, Chabrol).

E os antecedentes dessa crítica, a idade da razão da nova crítica cinematográfica francesa, apesar da juventude, estão justamente na revista Esprit, com Leenhardt e logo mais Bazin, e o processo oblíquo que vai do radicalismo "abstrato" de Esprit nos anos trinta (e do próprio Monier, patrono da revista) ao engajamento de Les temps modernes no pós Segunda Guerra mundial, hipótese nossa, em se pode seguir pari passu a correlação entra filosofia daquele tempo e a formação da moderna crítica de cinema francesa - daí o duplo interesse para fins da história ideológica recente da França.

Logo, a camada mais interior, algo mais profunda e talvez mais complexa historicamente, avançando um tanto mais a análise, e que tem a ver com pelo menos dois elementos chaves, está na posição política e intelectual dos pais fundadores dos $\mathrm{Ca}$ hiers. Serão eles os antigos colaboradores da Esprit, revista com a marca da resistência, não sem alguma ambiguidade até 1942, dirigida por Emmanuel Mounier ${ }^{10}$, lugar de preferência dos católicos de esquerda. Roger Leenhardt e André Bazin acabam

\footnotetext{
9 "Si le cinéma existe d'abord à travers les yeux de ceux que le voient, alors, sans aucun doute, il a " existé " plus fort à certains moments précis de son histoire. Ce livre [La cinéphilie, excerto nosso] prend pour point d'appui un moment où le regard sur le cinéma s'est fait avide, où les images, comme happées par les réappropriations de quelques spectateurs, se sont transformées en fragments de vie intime, oú les projections se sont faites culture de groupe à coups de discussions, d'écritures, de revues et de querelles. Ce fut l âge d'or de la cinéphilie en France, entre la Seconde Guerre mondiale et la Nouvelle Vague, prolongé jusqu'aux mobilisations de 1968, le février de l'affaire Langois, le mai d'une sortie définitive dans la rue de l'événement. D'un coup, hors de la salle obscure protégeant la cinéphilie classique." (Baecque, 2003, p. 11). Aqui, uma fenomenologia do espírito, em linguagem popular, da cinefilia francesa, e com ela, involuntariamente, uma chave de compreensão da própria filosofia francesa em questáo.

${ }^{10}$ Ver Judt, 2007. Sobre Monier veja-se as p. 30-31.
} 
por, pouco a pouco, construindo ali e nas imediaçóes, naturalmente com alguns outros, a "consciência" por assim dizer da cultura cinéfila que brota e se espraia ainda sob a ocupação, dando assim os primeiros esboços técnicos e teóricos de uma possível crítica cinematográfica em boa forma.

Não por acaso, Merleau-Ponty partirá de um conjunto de artigos algo técnicos de Leenhardt, mas sobretudo estéticos, cujo títulos seguem a seguinte sequência, $O$ ritmo cinematográfico ${ }^{11}$, pulicado em janeiro 1936, em Esprit, com continuaçáo em maio do mesmo ano, $A$ "prise de vue". Estes textos dáo ocasiáo para se pensar o modo como o filme constitui para si e por si mesmo uma temporalidade estética (ou estetizante) que lhe é típica. Tomemos duas passagens de Leenhardt:

Einseinstein fez um dia uma experiência que contém em potência toda a arte da tela [do cinema]. Ele filmou a cabeça de um homem parcialmente sorrindo, e depois, um caixão, uma criança brincado nua na neve, e um natureza morta (uma mesa posta, por exemplo). Depois, ele projetou sucessivamente numa tela a mesma cabeça de homem, precedida a cada vez de um desses quadros. $\mathrm{E}$ o mesmo sorriso, seguindo-se a cada tema, parecia sucessivamente doloroso, indiferente, divertido. Prova de que o cinema náo consiste na reproduçáo de imagens em movimento da realidade, o que dispensaria qualquer interesse estético, mas na sucessão de elementos diversos e escolhidos dessa realidade, cuja aproximação ordenada cria uma realidade nova, o que quer dizer, uma significação nova. De fato, para que a experiência seja perfeita, é necessário intervir não apenas a sucessão desses elementos, mas igualmente o tempo em que dura sua projeção. Por exemplo, o sorriso, para parecer divertido deve não ter senão uma aparição furtiva, o sorriso indiferente, uma duraçáo normal, o sorriso doloroso, estender-se. Assim completada, a experiência de Eiseinstein é uma definição exemplar do ritmo: uma ordem de quadros tal, e para cada um desses quadros (ou "planos") uma duração tal, que o conjunto produza a impressão buscado com o máximo de efeito. (Leenhardt, 1936a, p. 627-628)

A passagem e sua descrição são em boa medida retomadas por Merleau-Ponty em seu artigo, que estrategicamente lhe antecede uma digressão sobre a nova psicologia. E qual seria essa "nova psicologia”? A psicologia fenomenológica, cujo ensinamento chave é de que as condutas só podem ser compreendidas se inscritas em uma totalidade da qual elas são partes constitutivas, mas sem a qual, sem essa totalidade, sua inteligibilidade fica falhada e fatalmente prejudicada. A "estrutura do comportamento" exige que assumamos que a totalidade em que se inscreve um comportamento qualquer produz uma dinâmica que não é nem pode ser a mera soma dessas mesmas partes. Em sentido amplo é isso que, naqueles idos, se estrá a chamar

${ }^{11}$ Leenhardt, 1936a; 1936 b. 
de fenômeno, a possibilidade indefinida de algo poder fazer remissão ao que lhe é "anterior logicamente" sem propriamente escavar seu fundamento fora da esfera de sua aparição, condicionante decisiva para as filosofias da existência, e a nova pedra de toque da inteligibilidade do mundo. A correlação aqui é evidente: o sentido propriamente estético do cinema é de mesma ordem. Náo é tanto a matéria bruta que toma à realidade que lhe define, o que por certo fascinou os primeiros espectadores dos irmãos Lumière (as tomadas, a fotografia em movimento), mas sua organização sobre dois eixos: o material e sua ordem (seus elementos propriamente visuais), o temporal (a duração da exposição desses elementos). Leenhardt, depois de sua descrição sóbria, não se furta a acrescentar: é o ritmo, em sentido próprio, eis o ritmo cinematográfico, a operação que conjuga esses dois eixos. O que, por sua vez, diznos: é esse o modo de o cinema fazer sentido. E esse modo mantém as mesmas características que Merleau-Ponty já descrevera ao comportamento em seu livro La structure du comportement (1942) e que retoma aqui, na abertura que faz de seu artigo antes de chegar à descrição de Leenhardt, com a inflexão de que não é apenas a estrutura do comportamento funciona de maneira totalizante - recompondo-se permanentemente em um todo que náo é mera soma das partes - mas igualmente a próprio percepção assim opera, e é justamente essa operação da percepção (que não apenas não percebe por meio de partes do mundo sensível, mas permite-se "deduzir", à sua maneira, à maneira perceptiva, totalidades parciais por meio de perfis parciais dessa mesma totalidade). Há, portanto, uma chave de inteligibilidade do sentido propriamente estético do cinema que passa pelo modo da percepção organizar-se como sentido. Ocorre que essa organização não passa pelo juízo (como queria Descartes, na versão de Merleau-Ponty), mas pela operação, por assim dizer, imanente à própria percepção, o que não se dá, sem que igualmente se reabilite o mundo não mais como simples espaço geométrico, espaço abstrato, mas como sede do sentido "concreto", por assim dizer, em que o vermelho lanoso do tapete é apreendido justamente por ser de maneira simultânea vermelho $e$ lanoso. A breve menção a Kant da Crítica do juizo, no texto merleaupontyano tem igualmente a função de reforçar essa tese. Não voltamos ao mundo anímico, pré galileico, mas à reorientação das relaçóes entre sensibilidade e entendimento. Essa reorientação é o que a Crítica do juízo exige em relação à Crítica da razão pura, com a ressalva de que agora náo seriam mais um caso de juízo estético, mas a chave de uma nova mathesis universalis fundada no sensível. Salvo o último trecho, nada muito diferente da posição sartreana quando analisa a emoção: "Esse significado sabemos desde a origem o que é: a emoção significa à sua maneira o todo da consciência ou, se nos colocamos sob o plano existencial, o todo da realidade humana. Ela não é um 
acidente porque a realidade não é uma soma de fatos; ela exprime, sob um aspecto definido, a totalidade sintética humana em sua integridade” (Sartre, 2010, p. 17).

Podemos completar: "Afinal, o que se trata de mostrar ao renitente, que se surpreende com a afirmação de um sentido imanente aos signos, é que não há, por antecipação, nenhum divórcio entre o sensível e o inteligível. O que nos condena a esse divórcio é apenas o prejuízo 'objetivista' que teima em opor o signo à significação, assim como a res extensa se opóe à res cogitans” (Moura, 2001, p. 305). Será esse "sentido imanente aos signos" o que fará a passem de uma sequência de fotogramas ao cinema, do percebido qualquer à percepçáo como sentido imanente, e mais longe, e com maior complexidade, da percepção ao cinema.

Há um programa merleaupontyano, por assim dizer, sob o qual não cabe no espaço desse artigo entrar no mérito, que permite, por meio da compreensão da percepçáo e seus dispositivos, estabelecer uma medida de compreensáo, uma pedra de toque ao sentido das coisas em geral, e que, não sem razão, Merleau-Ponty aplica aqui ao cinema, mediado pelo texto de Leenhardt. Ora, que o cinema tenha sentido, que o cinema tenha valor estético, essas afirmaçôes de ordem geral são de pouquíssimo rendimento analítico, daí o pouco apelo do texto merleaupontyano, à primeira vista. Mas não se trata exatamente disso: o sentido que ele localiza no cinema, seu sentido propriamente estético, decorre de uma importante reorganização teórica em curso que tem como ponto nevrálgico as relaçóes entre sensibilidade e entendimento.

Ao se fazer o caminho inverso, entretanto, pode ser mais interessante e esclarecer o ponto que chamamos a atenção. Qual seria esse caminho? Assumir que o sentido estético do cinema, a construção de seu ritmo, decorre do modo como se exige da direção (da mise-em-scène) que "desestilize" o material que capta, que lhe dê uma "espontaneidade" (efeito da arte, e não do acaso) que lhe permita, por meio desse "rebaixamento", dessa "desestilização", escapar de um "objetivismo" que lhe deturpa o próprio sentido de imagem. A direção nada mais é que um tipo específico de redução da imagem bruta à imagem cinematográfica. Ora, o cinema exige o propriamente fílmico, não o literário ou o romanesco, que na produção cinematográfica não reduzida faria às vezes daquilo que Merleau-Ponty chama de preconceito objetivista. Mal resumido, significa que a linguagem cinematográfica precisaria de instâncias exteriores a ela mesma, a literatura, por exemplo, para que pudesse operar subsidiariamente. Ora, essa constatação está em perfeita consonância com o problema central da crítica cinematográfica nascente: descrever e defender o sentido imanente do cinema e por quais expedientes técnicos esse sentido se realiza. A crítica nascente, antecedente imediato do moderno cinema francês, está a postos para dizer que quem, do ângulo correto, póe-se a ver um filme, o que se vê, se olhar, é sua operação imanente, no nível da percepção. 
Reiteramos, sem entrar no mérito de programa merleaupontyano e de suas inflexões, tal movimento, com a passagem de Leenhardt:

Um diálogo, uma cena romanesca são criados e bastam-se a si mesmos. A construção romanesca - que pode ser inexistente - não fará senão agrupar, reforçar elementos elaborados, já plenos de mensagem. Ao contrário, a objetiva entrega ao cineasta uma matéria bruta. Que o tema lá seja igualmente imaginário, que se o tenha rodado com atores, nada muda. Estes devem interpretar do modo o mais naturalista, pois a potência de realidade que se depreende da tela é tal que a menor estilização a arruinaria. E o papel próprio da direção [da "mise-emscène], da realização (diferente da verdadeira criaçáo que é o ritmo por corte [decupagem] e montagem, será a de dar a impressão de que não há direção. (Leenhardt, 1936a, p. 631)

Para Merleau-Ponty, a autonomia estética do cinema, justificada pelos mesmos motivos que ele reencontraria na descrição fenomenológica da percepção reforça seu programa (e problema): a unidade ante-predicativa do fenômeno, que encontra seu fundamento da percepção como chave para decifração do "sentido nascente das coisas". Será esse pressuposto que se desdobra em uma espécie de contínuo ou inscrevese em uma imanência não estrita (não metafísica) que junta as duas pontas da experiência, sensibilidade e entendimento, sensível e pensamento, o que permitia o ganho analítico inédito: entender o pensamento por meio da pregnância sensível que o pressuporia. Do ponto de vista da crítica, seria como se essa reabilitação teórica do "concreto" (índice e problema), pois é disso que se trata, tornasse possível, ao reabilitar expedientes analíticos que, ao operarem de maneira imanente, ao se darem de modo imanente ao ato perceptivo, reconhecessem a autonomia estética da linguagem cinematográfica.

Se nós consideramos o filme como um objeto a perceber, nós podemos aplicar à percepção do filme tudo o que acaba de ser dito da percepçáo em geral. E ver-se-á que, desse ponto de vista, a natureza, a significaçáo do filme esclarecem-se e que a nova psicologia nos conduz precisamente às melhores observaçóes dos estetas do cinema. (Merleau-Ponty, 1996, p. 68)

O corolário dessa constatação repóe o problema do realismo cinematográfico, o correlato da crítica cinematográfica para o bordão filosófico da volta ao "concreto", tema central da então crítica cinematográfico nascente, e elevado a problema analítico chave nos melhores textos teóricos de André Bazin (da "ontologia da imagem fotográfica" ao "realismo poético" de Renoir), em alguma medida, aquele que recebe o bastão de Leenhardt e acelera a passada, constituindo-se como o mais importante e influente crítico cinematográfico francês, contemporâneo da mesma experiência da volta ao "concreto". 
Uma boa parte da filosofia fenomenológica ou existencial consiste a se espantar dessa inerência do eu ao mundo, e do eu ao outro, a descrever-nos esse paradoxo e essa confusão, a fazer ver o liame do sujeito e do mundo, do sujeito e dos outros, no lugar de os explicar, como faziam os clássicos, por algum recurso ao espírito absoluto. Ora, o cinema é particularmente apto a fazer aparecer a união do espírito e do corpo, do espírito e do mundo, e a expressão de um no outro. (Ibid., p. 74)

Completa Merleau-Ponty: "Se, pois, a filosofia e o cinema estão de acordo, se a reflexão e o trabalho técnico vão no mesmo sentido, é porque o filósofo e o cineasta têm em comum uma certa maneira de ver, uma certa visão do mundo que é aquela de uma geração.” (Ibid, p. 75)

Uma vez o que foi estabelecido, a saber, as condiçôes de comunicação entre filosofia e crítica, no momento em que, a filosofia francesa muda de pele e a crítica cinematográfica se instaura na estrita observação da autonomia estética de seu objeto, o cinema, podemos estender o olhar um pouco mais adiante, com o fim de constatar o quanto, mesmo as tomando como imaginárias, essas linhas que se estendem reforçam a correlação que localizamos pontualmente, a partir do texto merleaupontyano. Para tal, façamos uma volta, de Leenhardt a André Bazin, para retornar de André Bazin a Merleau-Ponty.

Daquele núcleo, bastante pedagógico no modo de exposição, em que Leenhardt apresenta as características inteligíveis mínimas para o reconhecimento da autonomia estética do cinematógrafo, André Bazin desdobra uma tese acerca da natureza da imagem fotográfica, a unidade morfológica do cinema, construída quase que, por assim dizer, em dois planos, em uma quantidade mínima de páginas, transformando paradoxalmente a extrema concisão em qualidade expressiva. Exatamente isso que se encontra em A ontologia da imagem fotográfica (Bazin, 2018, p. 27-34) ${ }^{12}$.

Lá está André Bazin, cadete de Leenhardt, mentor de François Truffaut (incialmente crítico, e crítico de grande estatura) a fazer algo que ele chama de ontologia da imagem fotográfica, de clara inspiração sartreana, o título e a tese. A tese, que pressupóe algo como uma história transcendental da figuração (em sentido amplo) e faz Bazin retroagir, não sem razão, ao Egito (do mesmo ponto em que se inicia a A História da Arte de Gombrich), a fim de repor uma tensão figurativa entre o simulacro e o duplo. Nessa origem hipotética, em parte o problema da gênese da

\footnotetext{
${ }^{12}$ Vale ainda o comentário de De Baecque: “André Bazin, même s'il participe du courant de pensée catholique lié à Emmanuel Mounier, a lui aussi subi l'influence déterminante de Sartre. Il est même un livre du philosophe que le critique de cinéma, dès 1940, a lu et relu, en soulignant de nombreux passages, les annotant avec compulsion, L'imaginaire : psychologie phénoménologique de l'imagination. Ce livre a joué un rôle crucial dans la formation d'André Bazin, comme le signale Dudley Andrew, car il relie l'art à l'ontologie" (Beacque, 2003, p. 42).
} 
imagem e as consequências dessa gênese: um outro fora do tempo autêntico, original do modelo, faz a imagem oscilar entre o duplo e o simulacro, o duplo que se separar perfeitamente da origem, o simulacro que pretende repor no outro o tempo autêntico do modelo. A múmia e a escultura de terracota, no interior das pirâmides, perfazem esse problema: com o fim último de escapar de um tempo original que submete a experiência à instâncias que necessariamente nos escapam. Tal tensão alcança seu estado ótimo de confronto e equilíbrio no Renascimento, agora retraduzida em termos de apresentação simbólica e apresentação mimética das imagens, que poderíamos superpor, a título de ilustração, às diferenças de preceptivas que havia entre os desenhistas e os coloristas, os florentinos e os venezianos, repondo um arco de problemas em torno da produção pictórica no Ocidente que vai do Renascimento ao esboroamento dessas preceptivas em meados do século XIX (aproximadamente), o que dá em outro conjunto d pressupostos para a produçáo das imagens pictóricas. A história que conta Bazin é muito espelhada em Malraux, e inadvertidamente mantém algo do charme positivista e teleológico dele.

Porém, tem um claro operador analítico: reconhecer o tempo específico do objeto que se inaugura com a reprodução mecânica das imagens, efeito do prodígio que passa a ser produzir imagens sem a mão humana, o duplo por excelência, perfeitamente separado de sua origem, perfeitamente replicado, efeito de um gesto completamente aleatório, apertar o disparador da câmera, por exemplo.

Assim, a imagem fotográfica, daí sua complexidade, não realiza o sonho de vencer o tempo, função que as múmias deveriam ter cumprido, ela transmuta o instante do clichê em uma duração indefinida, finita, da ordem da repetição, dá ao instante uma eternidade degradada. É a elevação de um tempo qualquer à condição de um simulacro de eternidade que nada mais que é que a repetição indefinida daquele instante capturado na gelatina de prata. Essa eternidade imprópria não é capaz de sair do tempo - a eternidade agostiniana que não se submete as medidas do tempo, tal como nas Confissóes -, é tão somente um instante repetido como se fosse eterno. A elevação imprópria desse instante redunda em um tipo de resíduo impróprio que caracteriza a imagem fotográfica: é sua ontologia.

Essa característica tem implicaçóes epistemológicas e psicológicas.

Por isso mesmo, a pintura já não passa de uma técnica inferior de semelhança, um sucedâneo dos procedimentos de reprodução. Só a objetiva nos dá, do objeto, uma imagem capas de "desrecalcar", no fundo do nosso inconsciente, a necessidade de substituir o objeto por algo mais do que um decalque aproximado: o próprio objeto, porém liberado das contingências temporais. A imagem pode ser nebulosa, descolorida, sem valor documental, mas ela provém por sua gênese da ontologia do modelo; ela é o modelo. (Bazin, 2018, p. 33) 
Como disséramos, as implicaçóes psicológicas e epistemológicas decorrem do mesmo efeito ontológico: a condições lógicas de duplo da imagem fotográfica garantem-lhe uma adesão análoga à adesão dispensada ao seu modelo, logo, seu efeito retórico tem um fundamento psicológico. Isso acaba por lhe dar um estatuto epistemológico que se na aparência seria pacífico, duplo ideal de sua origem, não o é implicitamente: a imagem fotográfica nos engana pois somos "psicologicamente" constrangidos a crer na inimputabilidade de seus meios de reprodução. Bazin, em outro texto (Ibid. p. 42-48), avança sobre isso, o que não é de menor importância, pois uma das condiçôes de arte de massa do cinema decorrem dessa adesão mental imediata à "verdade" da imagem, e da potência fetichista que isso implica.

Entretanto, a ontologia da imagem fotográfica fornece a semântica para a qual o cinema será a sintaxe: a linguagem cinematográfica será o modo de apreensão da temporalidade congelada na forma degradada de duração da imagem fotográfica com o fim de lhe inserir em outro regime temporal, que vem da associação com outras imagens.

Esse sentido basal do processo, Bazin vai afinando e sofisticando analiticamente. Em A evoluçâo da linguagem cinematográfica (Ibid., p. 101-120), um tipo de história de cinema que culmina com a profundidade de campo, cujos seus mestres e guias são Jean Renoir e Orson Welles, estende o raciocínio implícito na Ontologia da imagem fotográfica. O balanço estético que Bazin faz do problema - a montagem no cinema mudo, o destino do cinema em sendo falado, o cinema da estilização da imagem (em suas variantes pelo viés da montagem e pela manipulação pictural) e o cinema de realidade, ambos diferenças de modos de um incontornável realismo cinematográfico - é o sinal para nosso caminho de volta.

A questáo da profundidade de campo gira em torno de como ela representa uma mudança estrutural na linguagem cinematográfica. Seja em Jean Renoir de $A$ regra do jogo (La régle du jeu, Renoir, 1939, França), seja em Orson Welles de Cidadão Kane (Citzen Kane, Orson Welles, 1941, EUA), o incremento técnico das películas permite uma profundidade de campo na qual a cena se dá em uma complexidade nova, com vários planos de significados, em sentido próprio, inscrito no mesmo campo, em que o adensamento de sentido do plano pela profundidade do campo exige uma ediçáo em ato do espectador. A imagem, na origem, clara e inequívoca, torna-se ambígua e misteriosa. O que poderia ser entendido a primeira vista como um obstáculo ao realismo do cinema, a perda da univocidade da imagem, é seu contrário: a intensificaçáo do ambiguidade, efeito dessa redefinição conceitual da direção (mise-en-scène) que a profundidade de campo proporciona, redobra, do ponto de vista de Bazin, a aposta realista: o cinema vê mais que o simples olhar, ele dá a ver mais, seu realismo, se me permitem, é transcendental. 
$\mathrm{O}$ assunto deste artigo levaria a analisar as modalidades psicológicas dessas relações, quando não suas relações estéticas, mas poderá ser suficiente observar grosso modo: 1) que a profundidade de campo colocaria o espectador numa relação com a imagem mais próxima do que a que ele mantém com a realidade. Logo, é justo dizer que, independentemente do conteúdo da imagem, sua estrutura é mais realista; 2) que ela implica, por conseguinte, uma atitude mental mais ativa e até mesmo uma contribuição positiva do espectador à mise-enscène. (Bazin, 2018, p. 116)

Da ambiguidade (ou mistério) da profundidade de campo, reencontramos a profundidade ou mistério do campo perceptivo, em Merleau-Ponty. Seja em seu elogio à dúvida de Cézanne, seja em $O$ olho e o espirito, o problema geral da expressão é recolocado como corolário da constatação prévia de que há, efetivamente, uma região comum de significação - o fenômeno ou a existência - cuja investigação permita avançar na compreensão analítica de um conjunto de objetos realçados como legítimos objetos de uma expressão desse motivo originário. Evidentemente que está em curso, no escopo desse esforço e como item necessário desse programa, uma reforma das relaçóes entre sensibilidade e entendimento (que podem ser redobrados, na obra merleaupontyana, em corpo e espírito, natureza e cultura, matéria e pensamento, visível e invisível).

Ora, em a Dúvida de Cézanne o essencial, para efeito de nosso texto, é entender o lugar da dúvida mencionada. Se tomamos o impressionismo, como sintoma e causa da ruptura da visualidade pictórica que é posta em movimento na segunda metade do século XIX (em consonância com a emergência da fotografia, como nota Bazin), é possível reconhecer que seu primeiro expediente crítico, provavelmente o mais profícuo, é o de recuar em relação ao que se vê para capturar, figurativamente, o ato de ver. Está lá Monet na ponta de lança desse processo, transmutando a visualidade em seu instante constitutivo, a impressão, e com isso dando relevo a uma nova técnica pictural (uso de cores primárias e suas complementares, o gesto pictórico de compor o visível pelo acúmulo de pequenas manchas, etc.). Até aí, história sabida. Cézanne dá um passo adiante, por assim dizer, mas o melhor seria dizer, ele reformula o problema do visível, para ficarmos com o léxico merleau-pontyano, dando-lhe uma extensão mais decisiva. Ele aceita o programa inicial do impressionismo, mas não se limita a isso: ele pretende ver o que a desconstrução da visualidade clássica pela captura do instante da impressão visual deixaria ver por detrás dela. Daí o elogio a Poussin, campeão olímpico do classicismo (o que, a depender do ângulo, complicaria uma pouco a versão de Merleau-Ponty): o que ele vê por detrás da impressão instantânea do visível (elemento crítico, e, diríamos, do ponto de vista de Cézanne, negativo) é o que Merleau-Ponty chama das coisas em "estado nascente", e completamos com Merleau-Ponty, "ele [Cézanne] que pintar a matéria à medida 
em que se forma, a ordem nascente por uma organização espontânea” (MerleauPonty, 1996, p. 18). São as coisas, a "natureza” (que não é qualquer natureza) em uma região expressiva mais fundamental, mas cuja característica chave é a ambiguidade: a sua presença é instável, mais precária porque mais fundamental.

Não por acaso, isso levará Cézanne ao problema técnico da profundidade: "Não marcar nenhum contorno, isso equivaleria suprimir aos objetos sua identidade. Marcando apenas um, seria sacrificar a própria profundidade, isto é, a dimensão que nos dá a coisa, não como que estatelada diante de nós, mas como plena reserva e como uma realidade inesgotável. Por isso Cézanne seguirá numa modulação colorida o relevo do objeto e marcará em traços azuis vários contornos" (Ibid., p. 20).

A dúvida de Cézanne, finalmente, não está nele está no fundo que ele encontra ou reencontra na sua investigação do visível, o fundo por detrás da primeira camada de impressóes visíveis das coisas: como figurar as coisas naquele estado?

Ora, daí é que se pode partir uma nova ontologia, cujos esboços aparecem, melhor esquadrinhados, em $O$ olho e o espirito: "a pintura é o único a ter o direito de olhar sobre todas as coisas sem nenhum dever de apreciação. Dir-se-ia que diante dela, as palavras de ordem e de ação perdem sua virtude" (Merleau-Ponty, 1964, p. 14).

Vejamos as questóes que se põem, encaminhando-nos para o fechamento desse entrecho. Do cinema com objeto que se dá ao pensamento, da filosofia como pensamento que passa por objetos que lhe são estranhos ou não canônicos, da reflexão estética que estabeleça como tema central uma investigação do sensível (e do visível) capaz de reformar as relaçóes entre sensibilidade e entendimento. Nesse balanço o propósito foi mostrar que a variaçáo de temas - cinema, pintura, filosofia e crítica - não subverte certa unidade de ritmo: há um agenciamento comum. O ponto chave da dúvida de Cézanne é sintomático, e agora podemos explicar-nos melhor sobre o lugar da dúvida. O lugar da dúvida não é a "personalidade" ou a "psicologia" de Cézanne (no andamento do ensaio sobre Cézanne, Merleau-Ponty não deixa de transfigurar em trama de romance policial o problema do psicologismo), o lugar da dúvida é esse solo ontológico fundamental que a tenaz investigação da visibilidade (e do propriamente pictórico), que empreende Cézanne, encontra. Sua tarefa e destino passam a ser esse: como traduzir em meios pictóricos essa regiáo ontológica e precária, que dá a profundidade das coisas?

Nossa insistência nisso é segredo de polichinelo: é a profundidade de campo o elemento analítico e fílmico que Bazin elege como chave para a crítica e compreensão do cinema, o horizonte do cinema moderno. Será o elemento chave de sua resposta à crítica sartreana ao Cidadão Kane. Sartre que viu no filme de Welles um filme excessivamente afetado e intelectual não o viu direito: apesar de uma nota barroca na composição, o elemento chave da direção (mise-en-scène) é a 
profundidade de campo, cuja o adensamento de sentido do fotograma é o que dá um sentido formal a ambiguidade do protagonista, que não é meramente pessoal, mas objetiva. Melhor: o anti-herói (ou o herói moderno) Charles Foster Kane se explica igualmente pelo contexto, cuja inovação está em ser mostrado junto a ele, por meio da profundidade de campo.

Com isso, fechamos os rascunhos dessa aproximação. Para encerrar, lembremos de outra história. As filosofias do concreto, as filosofias da existência na França têm um ancestral em comum com a crítica de cinema que emerge na França em meados dos anos quarenta, na esteira da cinefilia: de algum modo, ambos os "gêneros" são efeito de uma experiência essencialmente francesa: a crítica mundana. Dos Salóes de Diderot, passando pelo Pintor da vida moderna de Baudelaire, cultiva-se essa conversação meio teórica meio imagética desde antes da Revolução. As novidades seriam duas, a emergirem em meados dos anos quarenta da década passada: que a filosofia voltasse a acionar esses dispositivos mundanos (críticos-conceituais) depois de um século de contenção, que a salas de cinema fossem o último dos salóes, os salóes ultramodernos por excelência, espaço, por excelência, para uma espécie de intermitência espiritual, agora em registro popular, destino inescapável do cinema. Não será sem razão que Godard dirá de Truffaut: o último crítico francês na linhagem direta de Diderot.

Concluamos, com essa descriçâo de um outro tempo, com o compromisso de outra era:

Mais tarde, Renoir trará consigo com mais destreza os testemunhos sociais sobre a realidade francesa de antes da guerra e conseguirá maravilhosamente a associação e o esclarecimento recíprocos da mensagem moral e do testemunho social, mas se esta mensagem continua igualmente válida entre os carvoeiros italianos de Toni, os operários tipográficos de $O$ crime de Monsieur Lange, os militares de $A$ grande ilusão, os pequenos burgueses de Um dia no campo e os grande burgueses de $A$ regra do jogo, é justamente porque Renoir, de todos seus avatares sociais, não se interessa senão pelas mesmas verdades morais, pois o realismo social é para ele uma maneira de experimentar e provar a permanência do homem e das suas questóes. Renoir é um moralista. (Bazin, 2016, p. 71)

A última glosa vem de Ismail Xavier: "Distante deste e de outros diagnósticos "sombrio", a cinefilia podia abrigar a aposta de Bazin, viver o mundo da reprodução mecânica como promessa de redençáo, sem a melancolia barroca de uma reflexáo mais recente (penso em Barthes a prenunciar a morte no clic da máquina), sem viver o vazio do simulacro que a poluição imagética de hoje nos reserva. Podia entáo esperar, como ocorrera no início do século, a harmonia de ciência e arte, espírito e matéria, técnica e estética, esta utopia da modernidade expressa de forma original 
na obra de Bazin, conto do cisne dos evangelhos do cinema, sem dúvida o mais brilhante” (Xavier, “Apresentação” in Bazin, 2018, p. 21).

Completamos, finalmente: essa é a mais legítima utopia da Ilustração Francesa, reatualizada em um contexto de grandes expectativas. Como dissera Meliès a propósito de um filme dos irmãos Lumière: as folhas mexem-se. Em algumas circunstâncias, é o melhor que vemos.

\section{Referências bibliográficas}

Baudelaire, C. (1992). Critique d'art, suivi de critique musical. Paris: Gallimard.

Bazin, A. (2016). O realismo impossivel. Belo Horizonte: Ed. Autêntica. (2018). O que é o cinema? São Paulo: Ed. Ubu.

Beacque, A. de. (2003). La cinephilie. Invention d'un regard, histoire d'une culture, 1944-1968. Paris: Fayard.

Baecque, A. de; Toubiana, S. (2001). François Truffaut. Paris: Gallimard.

Descombes, V. (1979). Le même et l'autre. Paris: Les éditions de minuit.

Gombrich, E. H. (2006). The Story of Art. Nova York: Ed. Phaidon.

Gomes, P. E. S. (2009). Vigo, vulgo Almereyda. São Paulo: Ed. Cosac Naify \& Ed. Sesc.

Leenhardt, R. (1936a). "Le rithme cinematographique”, Esprit, p. 627-632. (1936b). "La prise de vue", Esprit, p 254-56.

Merleau-Ponty, M. (1942). La structure du comportement. Paris: PUF. (1945). Phénoménologie de la perception. Paris: Gallimard. (1964). L'oil et l'esprit. Paris: Gallimard. (1966). Sens et non-sens. Paris: Gallimard.

Moura, C. A. R. (2001). Racionalidade e crise. São Paulo: Ed. Discurso \& Ed. UFPR. Porta, M. A. G. (2011). Estudos Neokantianos. São Paulo: Ed. Loyola. Paulo: Ed. Loyola. (2013). Edmund Husserl, psicologismo, psicologia e fenomenologia. São

Sartre, J.-P. (2010). Esquisse d'une théorie des émotions. Paris: Ed. Hermann.

Worms, F. (2009). La philosophie en France au XXe. siècle. Paris: Gallimard. Xavier, I. (2018). O discurso cinematográfico. São Paulo: Ed. Paz e Terra. 